\title{
CUL1 promotes trophoblast cell invasion at the maternal-fetal interface
}

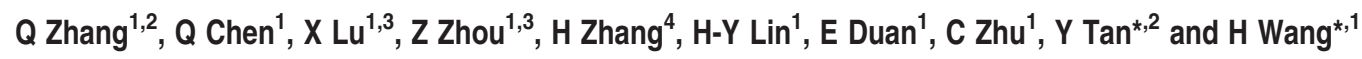

Human trophoblast progenitor cells differentiate via two distinct pathways, to become the highly invasive extravillous cytotrophoblast (CTB) cells (EVT) or fuse to form syncytiotrophoblast. Inadequate trophoblast differentiation results in poor placenta perfusion, or even complications such as pre-eclampsia (PE). Cullin1 (CUL1), a scaffold protein in cullin-based ubiquitin ligases, plays an important role in early embryonic development. However, the role of CUL1 in trophoblast differentiation during placenta development has not been examined. Here we show that CUL1 was expressed in CTB cells and EVT in the first trimester human placentas by immunohistochemistry. CUL1 siRNA significantly inhibited outgrowth of extravillous explants in vitro, as well as invasion and migration of HTR8/SVneo cells of EVT origin. This inhibition was accompanied by decreased gelatinolytic activities of matrix metalloproteinase (MMP)-9 and increased expression of tissue inhibitors of MMPs (TIMP-1 and -2). Consistently, exogenous CUL1 promoted invasion and migration of HTR8/SVneo cells. Notably, CUL1 was gradually decreased during trophoblast syncytialization and CUL1 siRNA significantly enhanced forskolin-induced fusion of choriocarcinoma BeWo cells. CUL1 protein levels in human pre-eclamptic placental villi were significantly lower as compared to their matched control placentas. Taken together, our results suggest that CUL1 promotes human trophoblast cell invasion and dysregulation of CUL1 expression may be associated with PE.

Cell Death and Disease (2013) 4, e502; doi:10.1038/cddis.2013.1; published online 21 February 2013

Subject Category: Experimental Medicine

Two major cell lineages of trophoblast have been identified during the early stages of human placental development: villous trophoblast and extravillous trophoblast. ${ }^{1,2}$ Villous cytotrophoblasts (CTBs), as trophoblast progenitor cells, follow one of the two existing differentiation pathways to form syncytiotrophoblast (STB) or extravillous cytotrophoblast cells (EVT). STB, covering the entire surface of the fetal villous tree, is the result of syncytialization, a dynamic process of continuous fusion of CTBs into the existing syncytium and delivery of the waste syncytial knots. STB establishes the important maternal-fetal barrier, ${ }^{2}$ which secrets hormones including human chorionic gonadotropin (hCG) and human placental lactogen (hPL), participates in immunological defense, and transports nutrients. EVT, including endovascular and interstitial EVT, are motile and highly invasive cells derived from CTBs after undergoing epithelial-mesenchymal transition (EMT). EVT infiltrates the endomyometrium to anchor the placenta and penetrates intima of the uterine spiral arteries to establish the feto-maternal circulation. Defects such as poor EVT migration/invasiveness, poor remodeling of the spiral arteries, and dysregulation of syncytialization, have been observed in severe pre-eclampsia $(\mathrm{PE})$, which in turn, may result in intrauterine growth restriction (IUGR). ${ }^{3}$

Trophoblast invasion is temporally and spatially regulated in an autocrine or paracrine manner by trophoblastic and uterine factors at the maternal-fetal interface. This regulation guarantees that the invasion of trophoblast cells only happens during the early stage of gestation and is restricted to the whole maternal endometrium and the upper third of myometrium. A complex network of cell types, mediators, and signaling pathways regulating trophoblast invasiveness has been described., ${ }^{4,5}$ For example, CTBs secrete matrix metalloproteinases (MMPs) and their tissue inhibitors (TIMPs), which help to balance and tightly control the invasion of EVT into maternal endomyometrium.

Cullin-based ubiquitin ligases, as a subtype of RING-type ubiquitin ligases, are multisubunit complexes. ${ }^{6,7}$ Seven mammalian cullin proteins have been identified, CUL1, CUL2, CUL3, CUL4A, CUL4B, CUL5, and CUL7. As one of the three cullins, which are highly conserved from yeast to humans, CUL1 acts as a scaffold protein in Skp1-CUL1-F-

\footnotetext{
${ }^{1}$ State Key Laboratory of Reproductive Biology, Institute of Zoology, Chinese Academy of Sciences, Beijing, China; ${ }^{2}$ Laboratory Animal Center, Chongqing Medical University, Chongqing, China; ${ }^{3}$ Graduate School of Chinese Academy of Sciences, Beijing, China and ${ }^{4}$ Department of Obstetrics and Gynecology, Beijing Obstetrics and Gynecology Hospital, Capital Medical University, Beijing, China

${ }^{*}$ Corresponding author: H Wang, Institute of Zoology, Chinese Academy of Sciences, Beichen West Road, Chaoyang District, Beijing 100101, China.

Tel: + 8610 64807187; Fax: + 8610 64807187; E-mail: wanghm@ioz.ac.cn

Or Y Tan, Laboratory Animal Center, Chongqing Medical University, Yixueyuanlu, Yuzhong District, Chongqing 400016, China.

Tel: + 8623 68486187; Fax: + 8623 68486187; E-mail: tanyee66@ @otmail.com

Keywords: cullin1; placenta; invasion/migration; syncytialization; pre-eclampsia

Abbreviations: CTBs, cytotrophoblasts; CUL1, cullin1; CK7, cytokeratin 7; ECM, extracellular matrix; EMT, epithelial-mesenchymal transition; EVT, extravillous cytotrophoblast cells; GCM1, Glial Cell Missing Homolog 1; hCG, human chorionic gonadotropin; hPL, human placental lactogen; IUGR, intrauterine growth restriction; MMP, matrix metalloproteinase; PE, pre-eclampsia; STB, syncytiotrophoblast; TC, trophoblast column; TIMP, tissue inhibitors of MMP

Received 14.05.12; revised 27.11.12; accepted 13.12.12; Edited by Y Shi
} 
box (SCF) complex and plays an important role in early embryonic development. ${ }^{8,9} \mathrm{CUL} 1^{-1-}$ mice are early embryonic lethal and dysregulation of cyclin $\mathrm{G} 1$ and cyclin $\mathrm{E}$ is observed in these mice. ${ }^{9}$ CUL3 or CUL4A null mice fail to develop beyond 7.5-day postcoitum (dpc) when the functional placenta has not been fully formed. ${ }^{10,11}$ Furthermore, mutations of several cullin genes have been identified in human growth retardation syndromes. ${ }^{12}$ For instance, mutation of CUL7 has been shown to be linked to 3-M syndrome and the Yakuts short stature syndrome. ${ }^{13,14}$ We have previously shown that CUL7 is a key inducer of the EMT of trophoblast lineages. ${ }^{15}$ However, the exact roles of CULs during placenta development have not been well characterized.

In this study, expression of CUL1 in placental compartments during early pregnancy, and between normal pregnant and pre-eclamptic placentas has been compared. The role of CUL1 in trophoblast differentiation, including invasion and syncytialization, has also been investigated. We show that CUL1 protein is highly expressed in CTBs and EVT, but not in STB of the placental villi from the first trimester, suggesting that CUL1 may regulate trophoblast invasion and migration. This is further confirmed by using human placental extravillous explant culture, in vitro cell invasion and migration assays combined with RNA interference (RNAi), overexpression and gelatinolytic zymography. Furthermore, we show that CUL1 levels are significantly downregulated during syncytialization of both primary human CTBs and choriocarcinoma BeWo cells. CUL1 siRNA upregulates the expression of GCM1, an essential transcription factor to promote syncytialization in human trophoblast cells, and also enhances forskolin-induced fusion of choriocarcinoma BeWo cells. Finally, we demonstrate that CUL1 protein levels in the human placental villi from pre-eclamptic patients are significantly lower as compared with matched control placentas. The above evidence supports a role of CUL1 in promoting invasion, but not syncytialization of human trophoblast cells. They also suggest that dysregulation of CUL1 expression may be associated with PE.

\section{Results}

CUL1 is highly expressed in human placental trophoblast cells exhibiting high invasive and proliferative capacities during the first trimester. We first evaluated CUL1 protein expression in human placental villi at different stages of pregnancy using immunohistochemistry. CUL1 protein was intensely and specifically stained at villous CTBs and trophoblast column (TC) during the first trimester, whereas no obvious immunostaining was observed in the STB (Figure 1Aa). In the term placenta, CUL1 was also expressed in CTB cells (Figure 1Ab) and moderate staining was observed in invasive EVT cells in the maternal decidua as defined by cytokeratin 7 (CK7) staining (Figure 1Ac and Ad). No CUL1 signaling was detected in maternal tissues (Figure 1Ac). In addition, expression of CUL1 in term placental villi was significantly lower than that in the first trimester based on western blottings (Figure 1B and $\mathrm{C} ; P<0.01$ ).

CUL1 siRNA inhibits migration of EVT in an extravillous explant culture model. Given the evident expression of
CUL1 in the TC and EVT in first trimester placentas, we next investigated whether CUL1 has any effect on the migratory capacity of trophoblast cells. Extravillous explants from first trimester human placental villi $(5-8 \mathrm{w})$ were cultured on matrigel-coated dishes. Under normal conditions, EVT cells migrate from the tip of the cell column and infiltrate the matrix during day 1 to day 3 of culture. The outgrowth distance as a result of EVT migration at the matrigel surface was measured at 24,48 , and $72 \mathrm{~h}$. At $24 \mathrm{~h}$ of culture, while explants anchored on matrigel and started to outgrow, no significant difference was observed between control siRNA and CUL1 siRNA-treated groups $(P>0.05)$ (Figure $2 \mathrm{Ab}$, Af and $\mathrm{B})$. At 48 and $72 \mathrm{~h}$ of in vitro culture, however, CUL1 siRNA-treated explants displayed a significant reduction in the distance of migration compared with the control siRNA (Figure 2Ac, Ag, Ad, Ah and B; $48 \mathrm{~h}: P<0.05 ; 72 \mathrm{~h}: P<0.01)$. Proteolysis of the extracellular matrix (ECM) by MMPs plays a crucial role in the regulation of cell motility. Gelatinases (MMP-2 and MMP-9) have been implicated in remodeling ECM in the trophoblast invasion process. ${ }^{16}$ Serum-free culture medium of the explant transfected with control siRNA or CUL1 siRNA was collected and the gelatinolytic activities of MMP-2 and -9 were measured by gelatin zymography. As shown in Figure 2C, the spent medium from the CUL1 siRNA-treated explants exhibited much lower level of pro-MMP-9 activities as compared with the control siRNA treated ones. Immunostaining of human extravillous explants for CK7 staining identified EVT outgrowths and CTB (Figure 2Dc and Dh), while integrin $\alpha 5$ identified EVT outgrowths (Figure 2Db and $\mathrm{Dg}$ ) on the serial sections. Immunofluorescent staining of CUL1 showed that CUL1 siRNA treatment substantially knockdown CUL1 expression in EVT of the explants (Figure 2Di) as compared with CON siRNA (Figure 2Dd)

CUL1 siRNA significantly inhibits invasion and migration of HTR8/SVneo cells. To further confirm the role of CUL1 in trophoblast invasion and migration, matrigel cell invasion and transwell cell migration models were included. Transfection efficiency, as evaluated by fluorescence signal in FITC-siRNA transfected HTR8/SVneo cells, was $\sim 90 \%$ (data not shown). siRNAs targeting CUL1 significantly decreased the expression of CUL1 protein in HTR8/SVneo cells (Figure 3a). Twenty-four hours after transfection, HTR8/ SVneo cells treated with CUL1 siRNA or control siRNA were plated onto matrigel or pure filter for following invasion or migration measurement $24 \mathrm{~h}$ later. Compared with the control siRNA, CUL1 siRNA significantly decreased the percentage of cells that invaded (Figure $3 \mathrm{~b} ; P<0.05$ ) or migrated (Figure 3c; $P<0.01$ ) to the other side of the filter.

To further confirm the function of CUL1, we overexpressed CUL1 (Supplementary Figure S1E) in HTR8/SVneo cells by transfection and found that exogenous CUL1 promoted migration $(P<0.05)$ and invasion $(P<0.01)$ of HTR8/SVneo cells as compared with control groups (Supplementary Figure S1A and B).

The proportion of apoptotic HTR8/SVneo cells was assessed by Hoechst 33258 staining in parallel. Compared with control or empty vector, apoptosis in CUL1 siRNA or overexpression plasmid transfected cells was negligible (Figure 4a; Supplementary Figure S1D; $P>0.05$ ). Further 
A
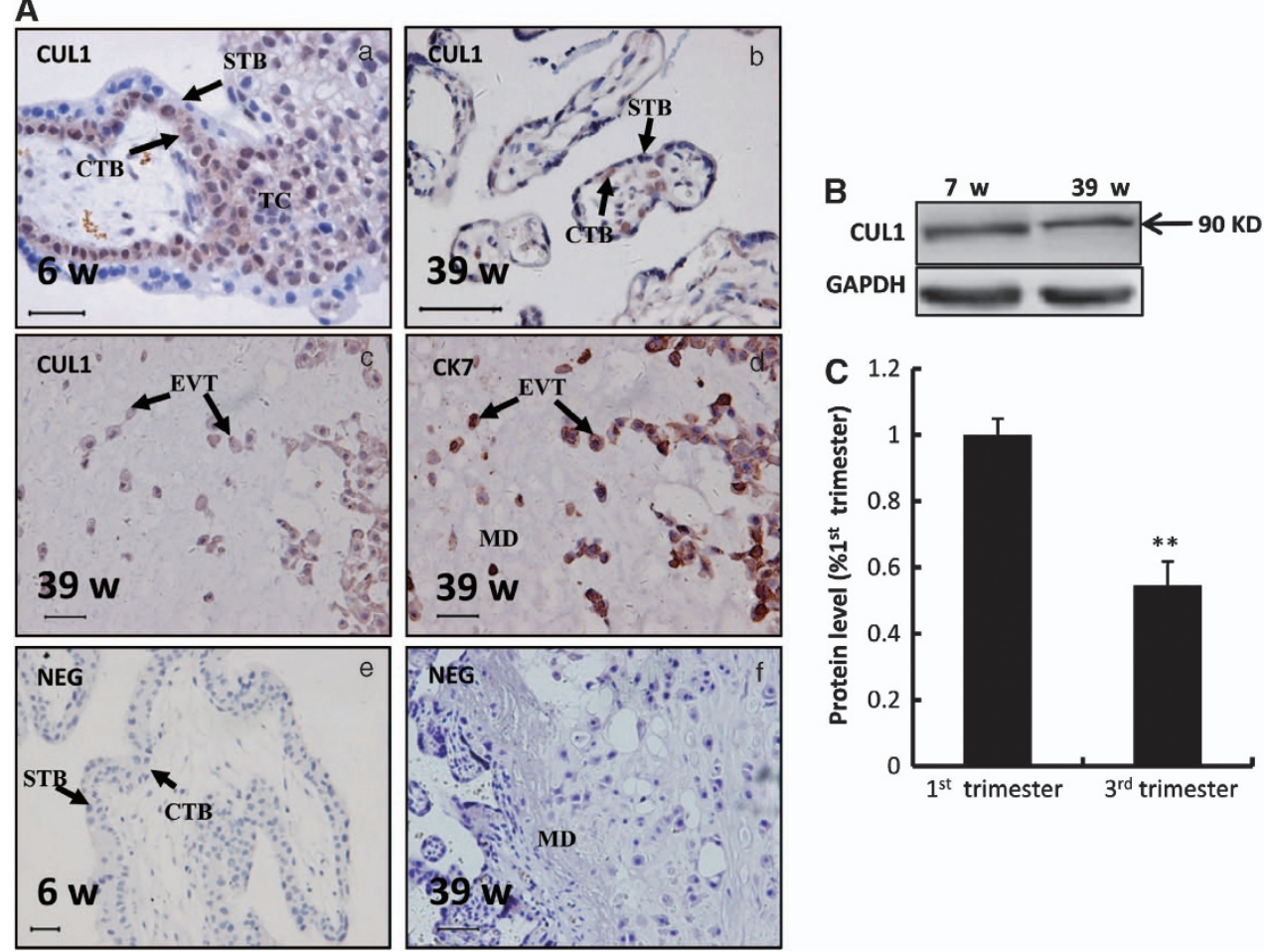

Figure 1 Expression of CUL1 in human placental villi at the first and the third trimesters. (A) Immunostaining of CUL1 and cytokeratin 7 (CK7) in normal human placental villi from the first and the third trimesters. (a) A placental villi from the first trimester. (b) A placental villi from the third trimester. (c, d) EVT invaded into the maternal decidua at the third trimester immunostained with CUL1 (c) and CK7, a marker of EVT (d). (e, f) Negative controls (NEG) in which normal lgG were used in place of primary antibody. CTB: cytotrophoblast cells; STB: syncytiotrophoblast; TC: trophoblastic column; EVT: extravillous trophoblast; MD: maternal decidua; Bar $=100 \mu \mathrm{m}$. (B) Western blotting of CUL1 in the human placental villi from the first $(n=3)$ and the third $(n=3)$ trimesters. GAPDH was used as a loading control (here and after). (C) Three experiments as in (B) were quantified by measuring the intensity of CUL1 protein bands relative to GAPDH controls $\left(t\right.$-test; $\left.{ }^{* \star} P<0.01\right)$

examination by western blotting showed that CUL1 siRNA did not increase expression of the pro-apoptotic cleaved caspase 3 in HTR8/SVneo cells (Figure 4b).

We then examined whether the changes in migration or invasion of HTR8/SVneo cells after CUL1 siRNA transfection or overexpression was a consequence of a decrease in cell proliferation. We observed that CUL1 RNA interference (RNAi) or overexpression had no obvious effect on cell proliferation at $24 \mathrm{~h}$ of additional culture after the transfection (Figure 4c; Supplementary Figure S1C; $P>0.05$ ), and significantly decreased proliferation of HTR8/SVneo cells only occurred until $72 \mathrm{~h}$ of culture (Figure $4 \mathrm{c} ; P<0.01$ ). These results suggested that the decreases in migration and invasion, which were observed at $24 \mathrm{~h}$ of cultures after CUL1 SiRNA or plasmid transfection for $24 \mathrm{~h}$, are not secondary to reduced proliferation and/or apoptosis.

We investigated the effects of CUL1 on gelatinolytic activities of MMP-2 and MMP-9 in HTR8/SVneo cells. Cells and supernatants were collected $48 \mathrm{~h}$ after siRNAs or plasmids transfection. Gelatin zymography assays (Figure 5a) and the statistical analysis revealed that compared with the control siRNA, CUL1 siRNA significantly decreased pro-MMP-9 but not pro-MMP-2 activities in the supernatants of HTR8/SVneo (Figure $5 \mathrm{~b} ; P<0.01$ ). Furthermore, we characterized the effect of CUL1 siRNA on the expression of TIMP-1 and TIMP-2, the tissue inhibitors of MMP-2 and MMP-9. We observed that the protein concentrations of TIMP-1 and -2 significantly increased in supernatants of CUL1 siRNA transfection as compared with control siRNA (Figure 5c).

CUL1 protein level is reduced during syncytialization. Real-time RT-PCR analysis showed that the transcript level of hCG and GCM1, factors that have been shown to be associated with syncytialization of trophoblast cells, was upregulated after CUL1 siRNA transfection in primary human CTBs (Figure 6a). This result suggested that there may be a negative relationship between CUL1 to syncytialization. To examine this, mononucleated CTB cells were isolated from human term placenta followed by in vitro culture. Spontaneous fusion of these primary cells led to the formation of multinucleated syncytium, which is characterized by increased immunostaining for $\beta$-hCG (Figure $6 \mathrm{~b}$ ). Interestingly, CUL1 protein was reduced at a time-dependent manner during the process of spontaneous syncytialization (Figure 6b and c; 0-24 h: $P<0.05$; 24-48 h: $P<0.05$; 0-48 h: $P<0.01)$. Furthermore, forskolin, which could induce fusion of BeWo cells (Figure 6d), caused a decrease of CUL1 protein in a concentration-dependent manner (Figure 6d). Morphologically, CUL1 siRNA had no significant effect on the fusion rate of BeWo cells (Supplementary Figure S2a and b; Figure 6e). Forskolin treatment significantly increased the number of multinucleated cells in BeWo cells as compared with the control group (Supplementary Figure S2a and c; 
A
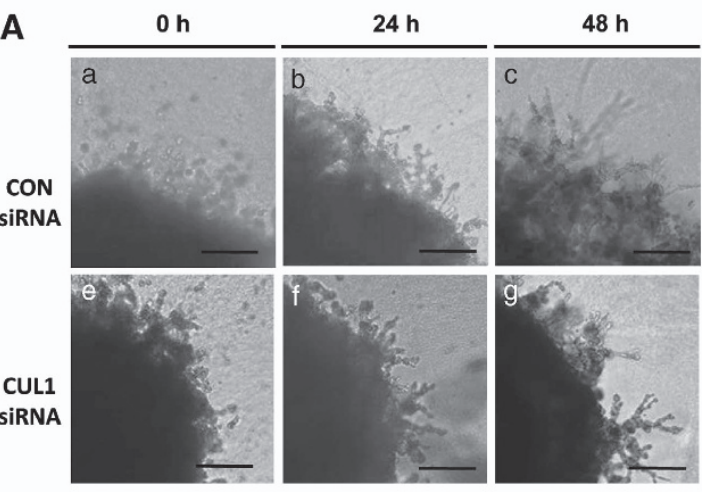

\section{B}

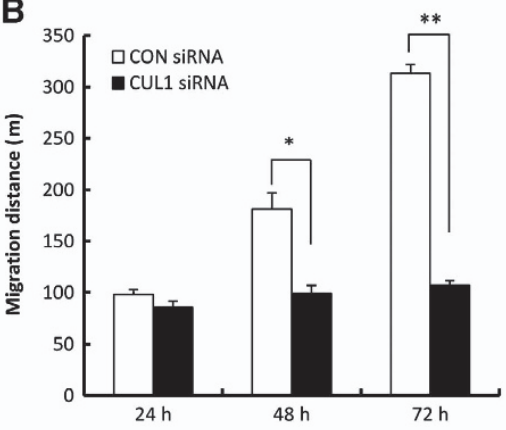

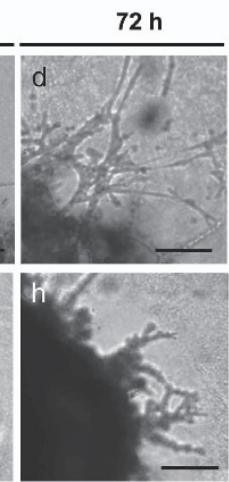

D
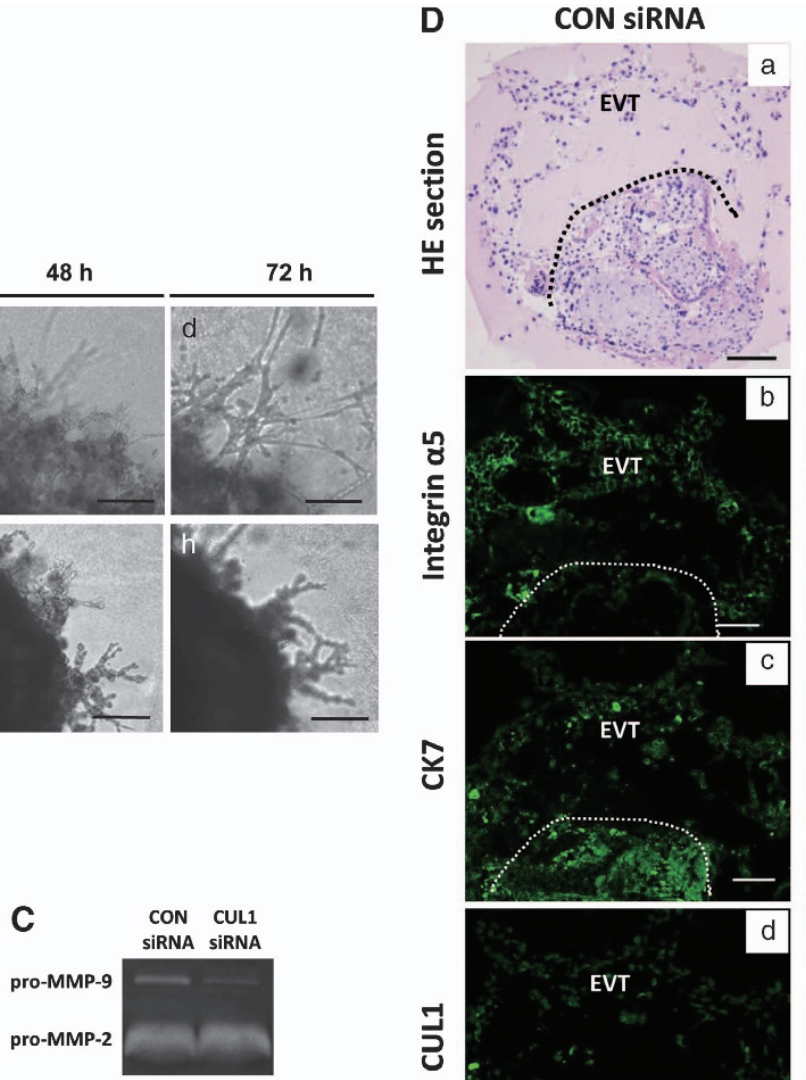
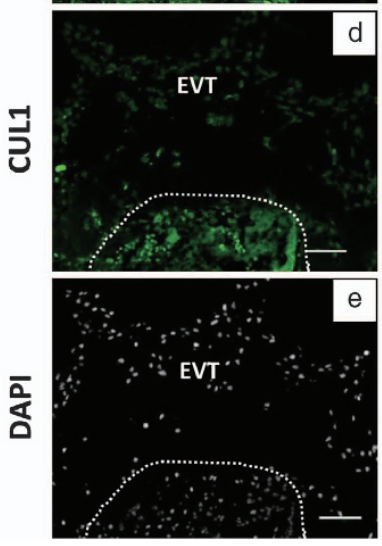

CUL1 siRNA
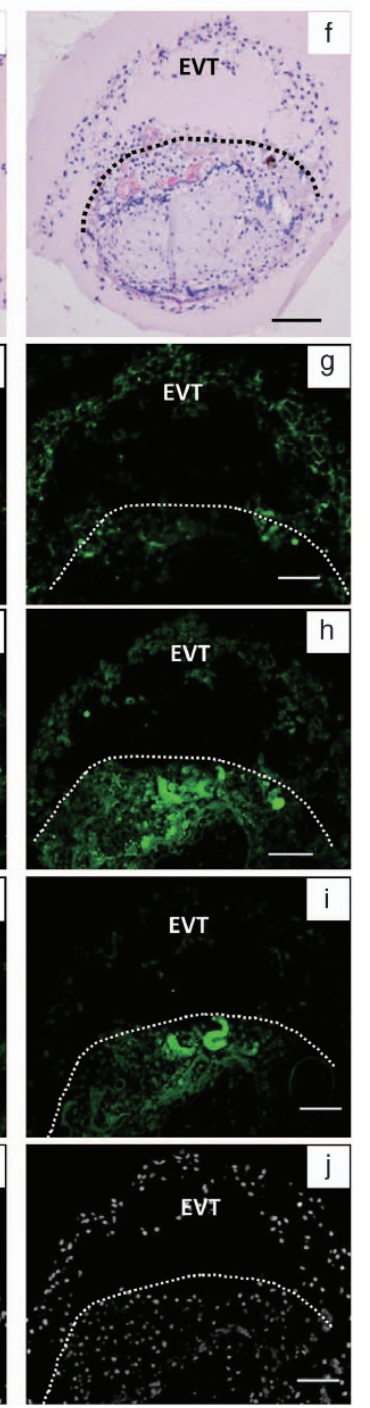

Figure 2 Silencing of CUL1 suppresses trophoblast outgrowth in extravillous explant cultures. (A) Extravillous explants from 5-8 weeks of gestation were maintained in culture on matrigel under low oxygen $\left(3 \% \mathrm{O}_{2}\right)$ tension. Serial pictures of explants incubated with CUL1 siRNA or control $(\mathrm{CON})$ siRNA were taken under the light microscope after 24,48 , and $72 \mathrm{~h}$ of culture in vitro. Bar $=100 \mu \mathrm{m}$. (B) A statistical assay of the migration distance of villous tips. Data are presented as mean \pm S.D. of three independent experiments ( $t$-test; ${ }^{*} P<0.05$; $\left.{ }^{* \star} P<0.01\right)$. (C) Serum-free culture medium of the explant transfected with indicated siRNAs was collected for gelatin zymography assay. (D) Examination of CUL1 knockdown efficiency after siRNA transfection. (a, f) Hematoxylin and eosin (HE) staining of CON or CUL1 siRNA-treated explants. Bar $=100 \mu \mathrm{m}$. (b, g) Immunofluorescent staining using integrin $\alpha 5$ antibody (green) identifies the EVT. Bar $=50 \mu \mathrm{m}(\mathrm{c}, \mathrm{h})$ Immunofluorescent staining using CK7 antibody (green) identifies the cytotrophoblast and EVT. Bar $=50 \mu \mathrm{m}$ (d, i) Immunofluorescent staining using CUL1 antibody (green) shows that CUL1 protein is lower in CUL1 siRNA-treated EVT (i) as compared with CON siRNA treated ones (d) at the same exposure time. Bar $=50 \mu \mathrm{m}$. (e, j) DAPI staining of sections d and i to visualize nuclei. Bar $=50 \mu \mathrm{m}$. $a, b, c$, and d are serial sections, so are $\mathrm{f}, \mathrm{g}, \mathrm{h}$, and $\mathrm{i}$. The region of EVT outgrowths is above the dashed lines

Figure 6e), and this increase was further enhanced by the transfection of CUL1 siRNA into the cells (Supplementary Figure S2c and d; Figure 6e).

CUL1 is downregulated in placental villi from PE patients. Inadequate trophoblast migration/invasion and spiral artery remodeling result in poor placenta perfusion, which mediates maternal injury including the onset of PE. ${ }^{17}$ Placental villi from pre-eclamptic patients and normal pregnancy controls of close gestational stages were dissected for protein extraction and immunoblotting. Western blotting (Figure 7a) and the statistical analysis (Figure 7b) showed that expression of CUL1 was significantly lower in the placental villi from pre-eclamptic patients as compared with control placentas $(n=11$, representatively shown in Figure $7 \mathrm{a}$ and $\mathrm{b}$, and the others were shown in the Supplementary Figure S3).

\section{Discussion}

In the current study, we have demonstrated that CUL1 promotes trophoblast invasion and migration, based on several lines of evidence. First, CUL1 was strongly and specifically expressed in TC and EVT cells invaded into 


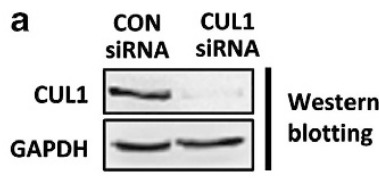

b

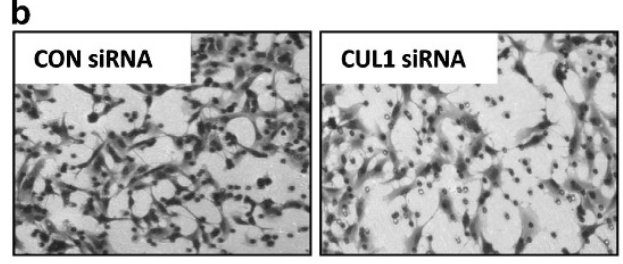

\begin{tabular}{cc}
\hline Treatments & $\begin{array}{c}\text { NO. of invaded cells in a } \\
100 \times \text { random field } \\
(\text { mean } \pm \text { SD) }\end{array}$ \\
\hline CON siRNA & $94.5 \pm 6.6$ \\
CUL1 siRNA & $65.8 \pm 6.2$ \\
\hline
\end{tabular}

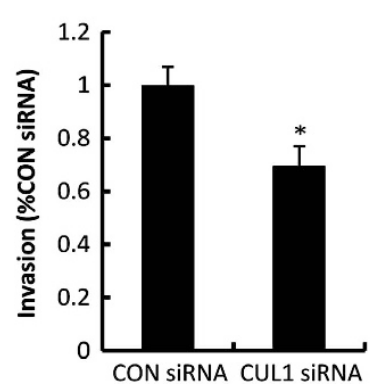

C
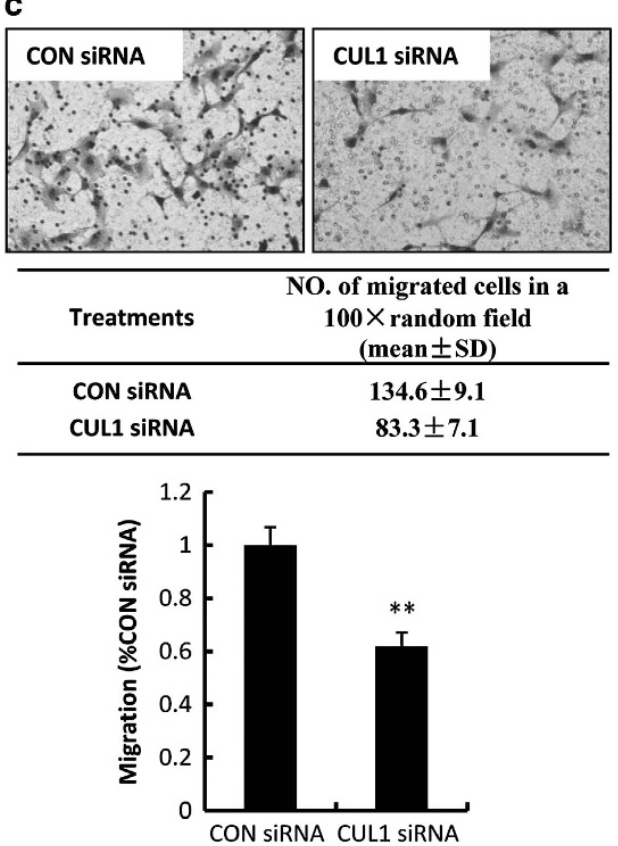

Figure 3 CUL1 siRNA inhibits invasion and migration of HTR8/SVneo cells. (a) Confirmation of RNA interference of CUL1 was shown by western blotting. (b, $\mathbf{c}$ ) Upper panels: representative images of filters containing invaded cells in matrigel invasion assay (b) and transwell cell migration assay (c) are shown; Middle panels: the number of invaded or migrated cells in a $100 \times$ random field; Lower panels: Statistical bar graphs showing the summary of three independent experiments $\left(t\right.$-test; $\left.{ }^{*} P<0.05 ;{ }^{* *} P<0.01\right)$
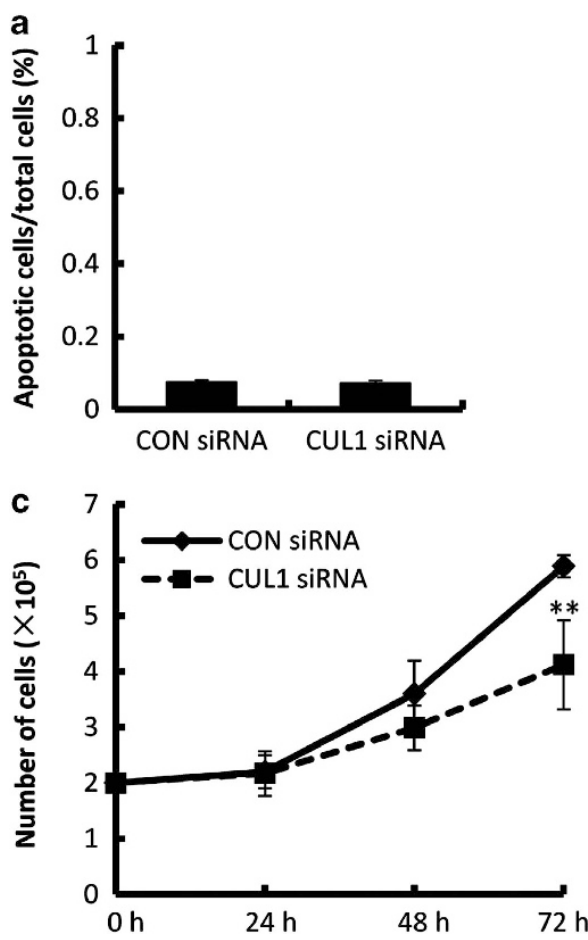

b

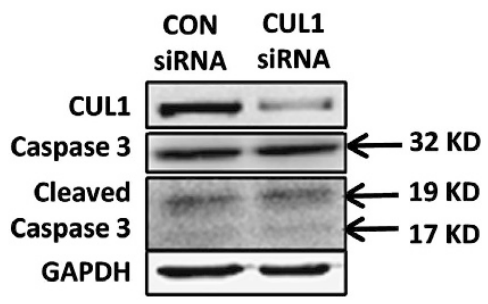

Figure 4 The effect of CUL1 siRNA on apoptosis and proliferation of HTR8/SVneo cells. (a) Ratio of apoptotic cells in a HTR8/SVneo cell population transfected with indicated siRNAs (t-test; $P>0.05$ ). (b) HTR8/SVneo cells transfected with indicated siRNAs were subjected to western blotting using indicated antibodies. (c) Proliferation assay of HTR8/SVneo cells transfected with indicated siRNAs over 3 days of culture $\left(t\right.$-test; $\left.{ }^{* \star} P<0.01\right)$ 

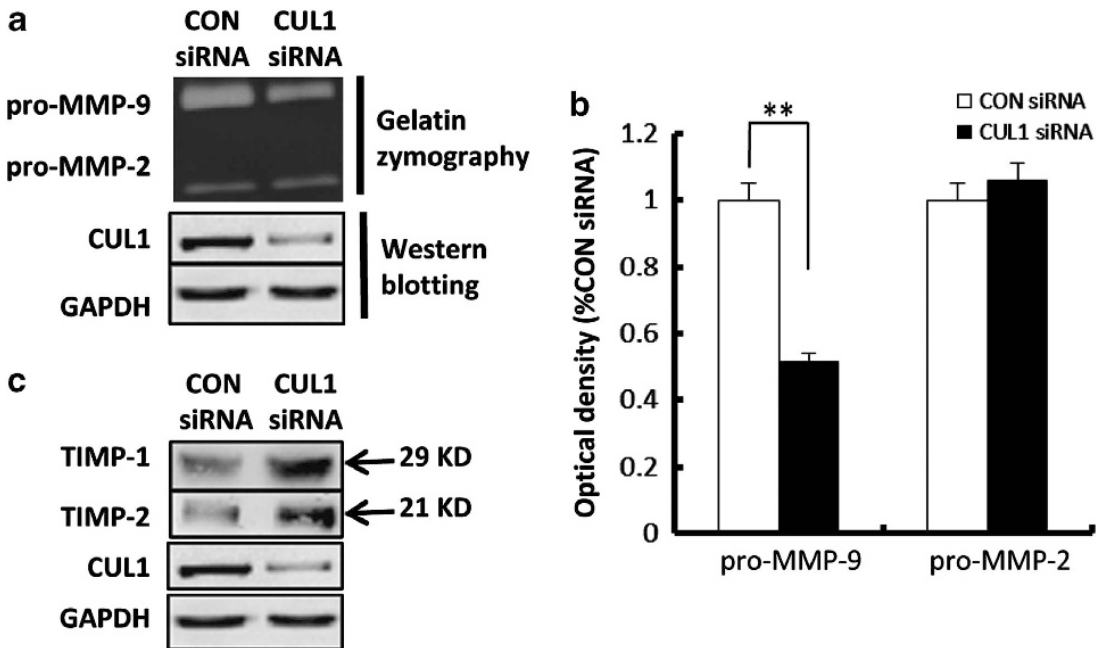

Figure 5 CUL1 siRNA inhibits the gelatinolytic activities of pro-MMP-9 and increased the expression of TIMP-1 and TIMP-2. (a) HTR8/SVneo cells transfected with indicated siRNAs were subjected to total proteins extraction and western blotting to detect expression of CUL1 (also in c). Serum-free culture medium was collected for gelatin zymography assay. (b) Statistical analysis of the zymographic results in (a) (t-test; $\left.{ }^{* \star} P<0.01\right)$. (c) Serum-free culture medium (for the detection of TIMP-1 and -2) or the whole cell proteins (for the detection of CUL1) of HTR8/SVneo cells transfected with indicated siRNAs were used for western blotting using indicated antibodies

maternal deciduae. Furthermore, CUL1 was highly expressed in placentas from the first trimester (when trophoblast cells exhibit high invasiveness), as compared with those from the third trimester. Second, CUL1 siRNA significantly inhibited trophoblast outgrowth and EVT migration in an in vitro extravillous explant culture model. Third, CUL1 promoted invasion and migration of trophoblast HTR8/SVneo cells in the matrigel cell invasion and transwell cell migration models by siRNA and overexpression experiments. Finally, downregulation of pro-MMP-9 and upregulation of TIMP-1 and -2 were accompanied by the decrease in migration and invasion after CUL1 siRNA transfection. Taken together, these data strongly suggest that CUL1 promotes invasion and migration of trophoblast cells.

CUL1 was identified as a member of conserved gene family using EST databases. ${ }^{18}$ Michel and Xiong ${ }^{19}$ found that CUL1 is part of a SCF complex, which mediates the ubiquitindependent degradation of cyclin G1 and cyclin-dependent kinase inhibitors. Staropoli et al. ${ }^{20}$ demonstrated that F-box proteins FBXW7 (F-box and WD40 domain protein 7) and CUL1, being in a distinct ubiquitin ligase complex, targets the ligase activity to cyclin $E$ in the regulation of neuronal apoptosis. The deficiency of SCF complex has implicated in the metastasis of breast cancer as a result of impairment in RhoA expression, cell migration and invasion. ${ }^{21}$ The present study adds a new function of CUL1 in placentation. Of interest, in relate to the results of CUL1, we previously found that another member of cullin family, CUL7, promotes migration of trophoblast cells and induces EMT of the trophoblast lineage via the upregulation of ZEB1 and SLUG, two transcriptional repressors of E-cadherin. ${ }^{15}$

In human placenta, EVT cells invasion involves degradation of ECM to promote this process. Migratory trophoblasts express MMPs, cathepsins, and urokinase plasminogen activator, ${ }^{5,22,23}$ whereas decidua produce TIMPs and plasminogen activator inhibitor (PAI), ${ }^{24,25}$ thereby restricting invasiveness. In this study, CUL1 siRNA was shown to be able to decrease the gelatinolytic activities of MMP-9 in HTR8/SVneo and explants culture media. The activities of MMPs in the extracellular space are inhibited by TIMPs. ${ }^{26}$ Our results showed that secretion of both TIMP-1 and -2 were increased in CUL1 knockdown cells. The precise mechanism through which CUL1 controls the levels or activities of TIMPs or MMPs, and whether these MMPs and TIMPs are direct targets for CUL1, require further investigation.

In this study, we have also evaluated the role of CUL1 in regulating syncytialization and demonstrated that (1) CUL1 was barely detectable in the multinucleated STB based on an immunohistochemical analysis on human placental villi from the first and third trimesters; (2) in a spontaneous syncytialization model of primary cultured term CTB cells, the level of CUL1 was time dependently decreased with the onset of syncytialization; (3) during the forskolin-induced fusion of BeWo cells, CUL1 level decreased with the elongation of forskolin treatment and CUL1 siRNA significantly enhanced forskolin-increased the number of multinucleated cells. The above evidence strongly suggests that CUL1 is possible to be a negative regulator for syncytialization.

Trophoblast syncytial fusion was shown to be regulated by factors such as fusion proteins (e.g., syncytin-1 and syncytin$2)$, proteases and cytoskeletal proteins as well as cytokines (e.g., Leukemia inhibitory factor, LIF), hormones, and transcription factors (e.g., GCM1). GCM1 is a critical transcription factor of syncytin-1, and thus plays an important role during syncytialization. ${ }^{27}$ As a syncytialization-promoting molecule, GCM1 is required for the differentiation of the human trophoblast. ${ }^{28}$ Previously, an interesting study by Chen and coworkers ${ }^{29}$ found that GCM1 is a direct target for CUL1, and the CUL1-SCF complex mediates ubiquitination and degradation of human GCM1. In this study, GCM1 mRNA was upregulated after CUL1 siRNA transfection in primary cultured term CTB cells, suggesting a non-ubiquitinationrelated role of CUL1 on GCM1, which requires further investigation. It is possible that CUL1, by multiple 


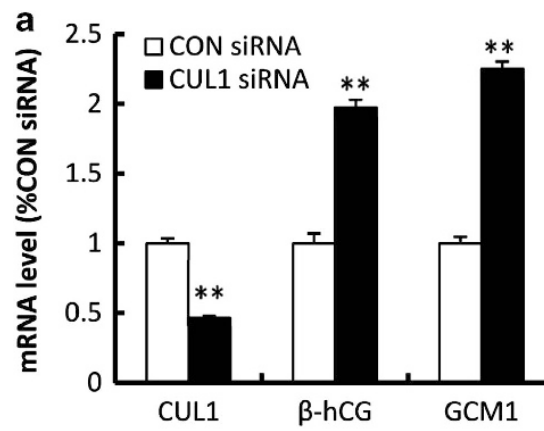

b

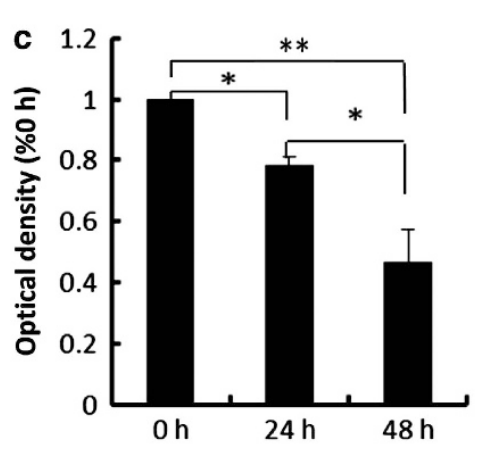

d
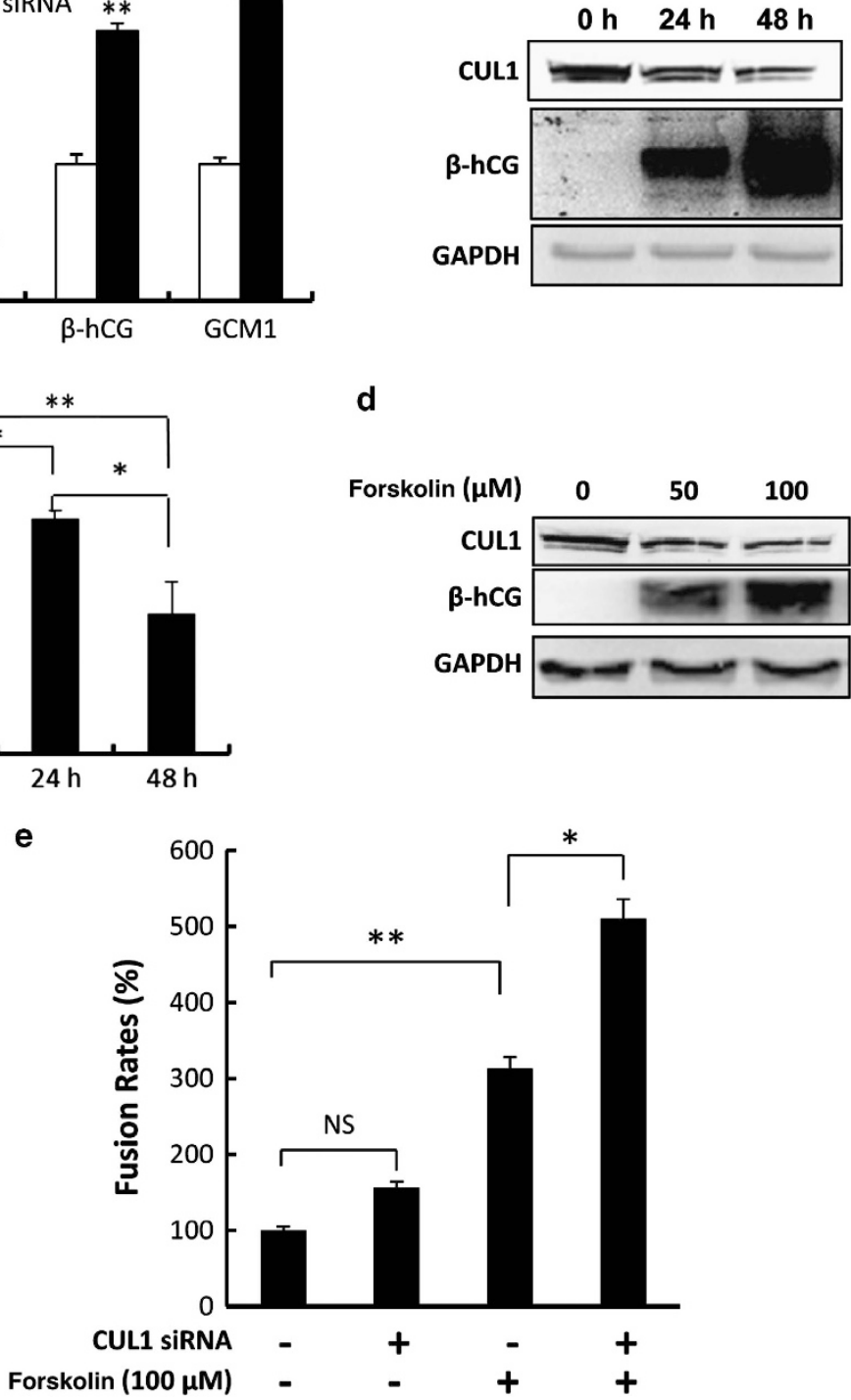

Figure 6 CUL1 protein level is decreased during syncytialization. (a) Real-time quantitative PCR analysis of CUL1, $\beta$-hCG, and GCM1 in the primary cultured cells treated with indicated siRNAs. The transcript level is expressed as percentage of CON siRNA, after normalization with $\beta$-actin ( $t$-test; $\left.{ }^{\star *} P<0.01\right)$. (b) Western blotting showing the expression of CUL1 and $\beta$-hCG in the primary trophoblast cells cultured for $0 \mathrm{~h}$ to $48 \mathrm{~h}$. (c) Statistical analysis of the western blotting results in (b) (one-way ANOVA; ${ }^{*} P<0.05$; ${ }^{* *} P<0.01$ ). (d) Western blotting showing the expression of CUL1 in BeWo cells treated with or without forskolin by using indicated antibodies. (e) Twenty-four hours after transfection with siRNAs (CON and CUL1), BeWo cells were treated with $100 \mu \mathrm{M}$ forskolin or methanol for $48 \mathrm{~h}$. Multinucleated cells were counted as indicated in 'Materials and Methods'. Statistical bar graph showed that CUL1 enhanced forskolin-induced syncytialization of BeWo cells (NS, $P>0.05 ;{ }^{*} P<0.05$; ${ }^{\star *} P<0.01$; ANOVA)

mechanisms, downregulates GCM1 expression and hampers the differentiation of the CTB cells into STB. The precise mechanism whereby CUL1 regulates EVT invasion needs to be further investigated. CUL1 appears to direct CTB cells invasive pathway rather than the fusion pathway.

$\mathrm{PE}$ is defined by the occurrence of gestational hypertension associated with proteinuria after 20 weeks of gestation in a previously normotensive woman. ${ }^{30}$ Impaired trophoblast invasiveness/migration, which results in poor spiral arterial remodeling and consequently inadequate placental perfusion, is believed to cause PE. ${ }^{31,32}$ In this study, we found that the level of CUL1 is relatively lower in the placentas from PE patients as compared with their matched controls (Figure 7;
Supplementary Figure S3, which may suggest that CUL1 is disrupted under pathological condition. Nevertheless, the elucidation of the mechanism underlying downregulation of CUL1 in PE placentas and the relationship between CUL1 and the onset of PE remains to be further investigated.

In summary, our present studies support an important role for CUL1 in promoting invasion/migration of trophoblast, and suggest a possible pathological mechanism of PE.

\section{Materials and Methods}

Tissue collection. Human placental tissues from the first trimester $(5-8 \mathrm{w})$ were obtained from healthy women undergoing legal abortion for nonmedical reasons (for immunohistochemical study, western blotting, and explant culture). 


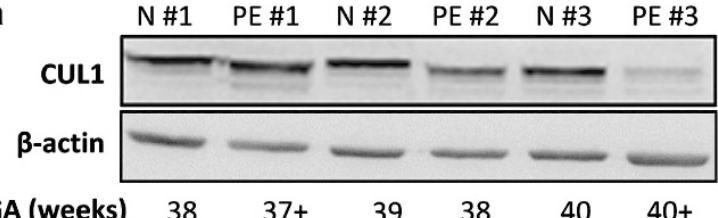

N: normal pregnant woman

PE: pre-eclamptic woman

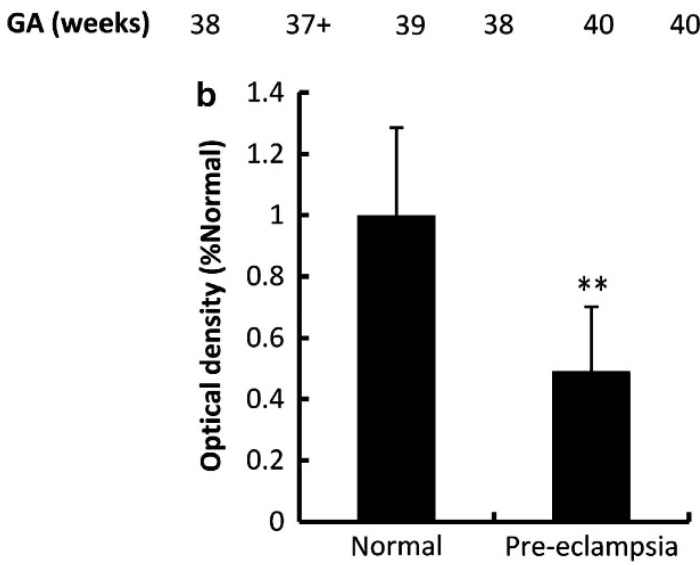

Figure 7 CUL1 is significantly downregulated in the human placental villi from PE patients. (a) Western blotting showing the expression of CUL1 proteins in the placental villi from normal pregnant $(n=3)$ or pre-eclamptic $(n=3)$ women. Three groups representing the 11 groups utilized in this study was shown. (b) Statistical analysis of the western blotting results in (a) $\left(n=11 ; t\right.$-test; $\left.{ }^{\star *} P<0.01\right)$

Term placentas (normal and pre-eclamptic; for western blotting and spontaneous syncytialization) were collected after cesarean birth. PE was defined as new onset of both hypertension (systolic/diastolic blood pressure $\geqslant 140 / 90 \mathrm{~mm} \mathrm{Hg}$ measured on two occasions of at least $4 \mathrm{~h}$ apart) and proteinuria ( $\geqslant 300 \mathrm{mg}$ per $24 \mathrm{~h}$ ) after 20 weeks of gestation. None of the PE patients involved in this study was complicated with obesity, chronic hypertension, gestational diabetes mellitus (GDM), or eclampsia. All the PE patients were aged 23-35, developed hypertension and proteinuria after gestational age of 32 weeks, and delivered at $36+$ to 40 weeks, which matched with normal controls. Among them, two patients were complicated with IUGR. Informed consent for placenta donation was obtained from all women. Ethical approval was granted by the Ethic Committee of the Beijing Obstetrics and Gynecology Hospital. All women were informed and signed consent to donate placenta for scientific research use. This study and the use of samples were under standard experimental protocols approved by the Ethics Committee of the Institute of Zoology, Chinese Academy of Sciences. For immunohistochemical study and western blotting, all the sample tissues were collected and stored in ice-cold DMEM (Gibco, Grand Island, NY, USA), transported to the laboratory within $30 \mathrm{~min}$ after surgery, and washed with ice-cold PBS before fixation (first trimester: $n=5$; normal third trimester: $n=5$ ) or protein extraction (first trimester: $n=3$; normal third trimester: $n=11$; PE third trimester: $n=11)$.

Cell culture, RNAi, and overexpression of CUL1. HTR8/SVneo cell line, derived from the invasive EVT, was used as a model for the first trimester EVT invasion and migration. HTR8/SVneo cells used in this study were from Dr. Benjamin K Tsang (Department of Obstetrics \& Gynecology and Cellular \& Molecular Medicine, University of Ottawa; Chronic Disease Program, Ottawa Health Research Institute, Ottawa, ON K1Y 4E9, Canada), as previously mentioned. ${ }^{33}$ Cells were cultured in RPMI 1640 (Gibco) containing 10\% fetal bovine serum (FBS), $100 \mathrm{lU} / \mathrm{ml}$ penicillin and $100 \mu \mathrm{g} / \mathrm{ml}$ streptomycin, and incubated under $5 \% \mathrm{CO}_{2}$ at $37^{\circ} \mathrm{C}$. For gelatinolytic zymography assay, cells were cultured in serum-free media.

For RNAi, cells were transfected with $100 \mathrm{nM}$ CUL1 siRNA (5'-CUAGAUACAA GAUUAUACAUGCGG-3', Invitrogen, Frederick, MD, USA; Genbank ID for CUL1: NM_003592.2) or the control siRNA (a universal negative control, Invitrogen) with Lipofectamine 2000 (Invitrogen, Carlsbad, CA, USA) as recommended by the manufacturer. The transfection efficiency was $>90 \%$ as measured by using fluorescence-labeled siRNA (Invitrogen).

For overexpression study, full-length human CUL1 coding sequence was amplified from HTR8/SVneo CDNA by PCR as described previously. ${ }^{19}$ Amplified CUL1 was cloned directly into a TA cloning vector, pGEM-T vector (Promega,
Madison, WI, USA), and subcloned into pFLAG-CMV4 vector using Nott, BamHI sites. In all, $5 \mu \mathrm{g}$ Flag-CUL1 plasmids were transfected into HTR8/SVneo cells at $70 \%$ confluence for $60 \mathrm{~mm}$ dish with Lipofectamine 2000 (Invitrogen) as recommended by the manufacturer. pFLAG-CMV4 empty vector transfected HTR8/SVneo cells serve as a control.

Twenty-four hours after siRNA or plasmids transfection, HTR8/SVneo cells were used for transwell assay, MTT assay, and Hoechst 33258 staining.

Fusion of BeWo cells after forskolin treatment. The human choriocarcinoma cell line BeWo (ATCC) was maintained in F12K medium (Sigma-Aldrich Inc., St. Louis, MO, USA) supplemented with 10\% FBS, 100 units/ $\mathrm{ml}$ penicillin, $100 \mathrm{units} / \mathrm{ml}$ streptomycin, and incubated under $5 \% \mathrm{CO}_{2}$ at $37^{\circ} \mathrm{C}$. BeWo cells were treated with forskolin at different concentrations $(0 \mu \mathrm{M}, 50 \mu \mathrm{M}$, $100 \mu \mathrm{M})$ after being starved. To test whether CUL1 siRNA has a role to play during forskolin-induced fusion of BeWo cells, CUL1 siRNA or control siRNA were transfected into BeWo cells for $24 \mathrm{~h}$ before being treated with forskolin or methanol (the vehicle control for forskolin) for $48 \mathrm{~h}$. To assess fusion rates, we performed multinucleated cell counting following $\mathrm{E}$-cadherin immunostaining. The fusion index is calculated as $[(N-S) / T] \times 100 \% .^{34}(N-S)$ is the number of fusion events, $N$ is the number of syncytial cell nuclei, $S$ is the number of syncytia, and $T$ is the total number of nuclei.

Explant culture. The explant culture was performed as described previously. ${ }^{35}$ In brief, small pieces of tissues $(2-3 \mathrm{~mm})$ from tips of first trimester human placental villi $(5 \mathrm{w}-8 \mathrm{w})$ were dissected and explanted in Millicell-CM culture dish inserts $(0.4 \mu \mathrm{m}$ pore size, Millipore, Carrigtwohill, Co., Cork, Ireland) pre-coated with phenol red-free matrigel substrate (Becton Dickinson, Bedford, MA, USA). Inserts were placed into 24-well culture dishes (Costar, Cambridge, MA, USA). The explants were cultured in serum-free DMEM/F12 media with $100 \mathrm{IU} / \mathrm{ml}$ penicillin and $100 \mu \mathrm{g} / \mathrm{ml}$ streptomycin at $3 \% \quad \mathrm{O}_{2} / 5 \% \mathrm{CO}_{2} / 92 \% \mathrm{~N}_{2}$. Placental villi, anchored on matrigel and successfully initiated to outgrow, were used for the subsequent experiments and referred to as $0 \mathrm{~h}$. EVT sprouting and migration from the distal end of the villous tips were recorded daily for up to 4 days. The extent of migration (i.e., the distance from the cell column base to the tip of the outgrowth) was measured at defined positions with SPOT software (SPOT Imaging Solutions, a division of diagnostic instruments, Inc., Sterling Heights, MI, USA). To test the effect of CUL1 on the migration of EVT, siRNA specifically targeting CUL1 $(500 \mathrm{nM})$ or an equal concentration of the control siRNA was introduced into two wells of culture media. All explant experiments with cultured villi were repeated three times. For each time, six explants were analyzed for both CUL1 siRNA and control groups (12 in total), which were obtained from 
three independent placentas (four from each). And the four samples from each placenta were divided into two parts, two for CUL1 siRNA and two for control.

Isolation and culture of term villous CTBs. Human term placentas were obtained after elective cesarean section from uncomplicated pregnancies with informed consent. Villi were isolated by trypsin/DNase I digestion of minced chorionic tissue and mononucleated cells were purified by density gradient centrifugation as previously described. ${ }^{36}$ Cells were seeded at a density of $1.0 \times 10^{6}$ in $35 \mathrm{~mm}$ dishes and cultured in DMEM supplemented with $10 \%$ FBS (Gibco) under $5 \% \mathrm{CO}_{2}$ at $37^{\circ} \mathrm{C}$. After $2 \mathrm{~h}$, the dishes were washed gently to remove dead cells and blood corpuscles.

Immunohistochemistry and immunofluorescence. Immunohistochemistry was performed on formalin-fixed, paraffin-embedded $5 \mu \mathrm{m}$ sections using the biotin-streptavidin-peroxidase (SP) and diaminobenzidine (DAB) kit (Zhongshan Golden Bridge Crop., Beijing, China), as previously reported. ${ }^{37}$ Sections were dewaxed in xylene and rehydrated through a gradient of ethanol. Slides were boiled in citrate buffer $(10 \mathrm{mM}$ citrate sodium, $10 \mathrm{mM}$ citric acid, $\mathrm{pH}$ 6.0) for $15 \mathrm{~min}$ to retrieve antigen, and incubated with $3 \%$ hydrogen peroxide in methanol for $10 \mathrm{~min}$ to quench endogenous peroxidase activity. After blocking with normal goat serum for $20 \mathrm{~min}$, sections were incubated with primary antibodies against rabbit monoclonal CUL1 (LS-C90294 (9E237) LifeSpan Biosciences, Inc., Seattle, WA, USA) at a 1:50 dilution, or mouse monoclonal Cytokeratin 7 (ab20206 (LP1K), Abcam, Cambridge, MA, USA) at a 1:200 dilution overnight at $4^{\circ} \mathrm{C}$. After washing in PBS, the sections were incubated with biotinylated secondary antibody and stained by using a diaminobenzidine kit. The negative control experiment was performed by replacing the primary antibody with goat serum or IgG from the same species where the primary antibodies were generated.

To demonstrate the knockdown efficiency of CUL1 in extravillous explants, sections of the first trimester explants were incubated with rabbit polyclonal integrin a5 (1: 100, SC-10729 (H-104), Santa Cruz Biotechnology, Santa Cruz, CA, USA) and rabbit monoclonal CUL1 (1:50, LS-C90294 (9E237) LifeSpan) overnight at $4{ }^{\circ} \mathrm{C}$. After washing in PBS, the sections were incubated with secondary antibody to fluorescein isothiocyanate (FITC)-conjugated anti-rabbit lgG (Zhongshan Golden Bridge Crop.) at a 1:100 dilution for $30 \mathrm{~min}$ at $37^{\circ} \mathrm{C} .4^{\prime}, 6^{\prime}$-Diamidino-2phenylindole (DAPI) was used to stain the nuclei of the explants.

Matrigel cell invasion and transwell cell migration assays. Invasion was performed in matrigel (Becton Dickinson)-coated transwell inserts $(6.5 \mathrm{~mm}$, Costar) containing polycarbonate filters with $8 \mu \mathrm{m}$ pores size, as described previously. ${ }^{37}$ Briefly, the inserts were pre-coated with $50 \mu \mathrm{l}$ of $1 \mathrm{mg} / \mathrm{ml}$ matrigel matrix at $37^{\circ} \mathrm{C}$ for $4 \mathrm{~h}$ for gelling. HTR8/SVneo cells $\left(1 \times 10^{5}\right.$ in $200 \mu \mathrm{l}$ serum-free media), transfected with siRNA or plasmids for $24 \mathrm{~h}$, were plated in the upper chamber, whereas medium with $10 \%$ FBS was added to the lower well. After incubating for $24 \mathrm{~h}$, the cells on the matrigel side of the insert were removed by cotton swab. The inserts were then fixed in methanol for $10 \mathrm{~min}$ at room temperature and stained with hematoxylin and eosin (Zhongshan Golden Bridge Corp.). Cells invaded to the other side of the insert were counted under a light microscope (Olympus IX51, Tokyo, Japan) in five random fields at a magnification of $\times 200$. The assay was repeated three times, and the results were represented as means of invasion percentage (\%) \pm S.D. in cell invasion compared with control. Conditional culture medium was collected for gelatinolytic activity assay.

The migratory ability of HTR8/SVneo cells was determined by their ability to cross the $8-\mu \mathrm{m}$ pores on the filter of the migration chambers as previously reported. ${ }^{37}$ Methods used in cell migration assay were similar to matrigel invasion assay except that the transwell insert was not coated with matrigel.

Hoechst 33258 staining. Hoechst 33258 staining was performed as previously reported. ${ }^{38}$ In brief, $25 \mu$ l of cell suspension (around $0.5 \times 10^{4}$ cells) was incubated with neutral-buffered formalin $(10 \%)$ containing Hoechst 33258 dye $(12.5 \mathrm{ng} / \mathrm{ml})$ (Sigma). The cell suspension was placed onto a microscopic slide covered by a coverslip. The cells, producing cell fragments called apoptotic bodies, are defined as apoptotic cells. The number of apoptotic cells in 200 total cells was counted under a fluorescent microscope (Olympus IX51). To avoid counting bias, the counter was blinded to sample identity.

Cell proliferation assay. HTR8/SVneo cells transfected with CUL1 siRNA or the control siRNA for $24 \mathrm{~h}$ were seeded at a density of $2.0 \times 10^{5}$ cells per well onto a six-well plate. And the seeding time was deemed as $0 \mathrm{~h}$. The plate was put in an incubator and the number of cells was counted every $24 \mathrm{~h}$.

MTT assay. Twenty-four hours after plasmids transfection, HTR8/SVneo cells were used for MTT assay. Briefly, HTR8/SVneo cells were seeded at $0.5 \times 10^{4} /$ well in 96-well plates. The culture medium was changed after $20 \mathrm{~h}$ to $100 \mu \mathrm{l}$ MTT reagent (3-[4,5-dimethylthiazol-2-yl]-2, 5-diphenyltetrazolium bromide; Apllygen Corp., Beijing, China). The MTT reagent was gently removed $4 \mathrm{~h}$ later and $100 \mu \mathrm{l}$ DMSO was added in each well. The optical density of each well was measured at $570 \mathrm{~nm}$ wavelengths (Beckman DU530, Fullerton, CA, USA). The experiment was performed in triplicates.

Reverse transcription and real-time PCR. Total RNA was extracted from HTR8/SVneo cells using TRIzol regent (Invitrogen) and purified as described according to the manufacturer's instructions. Two micrograms of RNA were reverse transcribed in a 20- $\mu$ l reaction containing Superscript II reverse transcriptase (Invitrogen) and incubated for $50 \mathrm{~min}$ at $42^{\circ} \mathrm{C}$ and $15 \mathrm{~min}$ at $72{ }^{\circ} \mathrm{C}$.

Real-time PCR was performed using the TaKaRa SYBR Premix Ex Taq Il kit and on an ABI Prism 7500 Real-Time PCR System in triplicates in $25 \mu$ volume. A total of $2 \mu \mathrm{l}$ of CDNA were mixed with $1.6 \mu$ l primers, $10 \mu \mathrm{l}$ SYBR Premix Ex Taq II and $0.4 \mu \mathrm{l}$ ROX Reference Dye II. The PCR program was initiated at $95^{\circ} \mathrm{C}$ for $30 \mathrm{~s}$, followed by 40 thermal cycles of $5 \mathrm{~s}$ at $95^{\circ} \mathrm{C}$ and $34 \mathrm{~s}$ at $60^{\circ} \mathrm{C}$. A melting curve for primer validation and a template standard curve were performed to show template independent amplification results. The comparative CT method (ABI technical manual) was used to analyze the real-time PCR. The expression of the GCM1 gene (Forward: 5'-CAGCCATGTACGTTGCTATCCAGG-3', Reverse: 5'-AGGTCCAGA CGCAGGATGGCATG-3'), CUL1 Forward: 5'-TGGGGCACCACAGAGATGCG-3', reverse: $5^{\prime}$-GGGGTTCTGGCTCCGGGTTG-3'; $\beta$-hCG Forward: $5^{\prime}$-GAGCTCAC CCCAGCATCCTATCACC- $3^{\prime}$, reverse: $5^{\prime}$-TTGATGGGGCGGCACCGTGG-3' was normalized to the geometric mean of $\beta$-actin (Forward: $5^{\prime}$-CAGCCATGTACG TTGCTATCCAGG-3', Reverse: 5'-AGGTCCAGACGCAGGATGGCATG-3') and expressed as fold change relative to negative controls $(n=5)$.

Western blotting. Proteins were extracted from cells or tissues with whole cell lysis buffer (50 mM HEPES, $150 \mathrm{mM} \mathrm{NaCl}, 1 \mathrm{mM}$ EGTA, $10 \mathrm{mM}$ sodium pyrophosphatate, $1.5 \mathrm{mM} \mathrm{MgCl}_{2}, 100 \mathrm{mM} \mathrm{NaF}, 10 \%$ glycerol, and $1 \%$ Triton $\mathrm{X}$-100) containing an inhibitor cocktail ( $1 \mathrm{mM}$ phenylmethylsulfonylfluoride, $10 \mu \mathrm{g} /$ $\mathrm{ml}$ aprotinin, and $1 \mathrm{mM}$ sodium orthovanadate). Culture media were concentrated using Microcon YM-3 centrifugal filter (Millipore). The protein concentration was measured using the Bradford method of protein quantitation by spectrophometry at $595 \mathrm{~nm}$ (Beckman DU530). Thirty micrograms of denatured proteins per well were subjected to SDS-PAGE according to standard protocols. Separated proteins were transferred electrophoretically onto a pure nitrocellulose blotting membrane (Pall Corporation, Pensacola, FL, USA). After being blocked with 5\% skim milk for $1 \mathrm{~h}$ at room temperature, the membrane was sequentially incubated with primary antibodies against CUL1 (1:500 ab2964, Abcam), TIMP-1 ( $1: 200$, SC-5538, Santa Cruz), TIMP-2 (1:200, SC-5539, Santa Cruz), caspase 3 (1:200, SC-7272, Santa Cruz), cleaved caspase 3 (1:500, 9664, Cell Signaling Technology, Beverly, MA, USA), $\beta$-hCG (1:500, ab9582, Abcam), $\beta$-actin $(1: 2000,4970$, Cell Signaling Technology) and GAPDH $(1: 20000$, ab37187, Abcam) overnight at $4{ }^{\circ} \mathrm{C}$, and washed three times for 10 min per wash with TBST. A subsequent incubation with monoclonal HRP-conjugated antibody was carried out for $1 \mathrm{~h}$ at room temperature in $5 \%$ skim milk, and three times of washes with TBST were performed. Immunoreactive bands were detected using enhanced chemiluminescence (Pierce Chemical Co., Rockford, IL, USA).

Gelatin zymography. Analysis of gelatinolytic activity was performed using $10 \%$ (w:v) polyacrylamide gels containing $0.5 \mathrm{mg} / \mathrm{ml}$ gelatin (Difco Laboratories, Detroit, MI, USA) as previously reported. ${ }^{16}$ Briefly, conditioned medium was diluted in $4 \times$ sample buffer ( $8 \%$ SDS (w:v), $0.04 \%$ bromophenol blue (w:v), $0.25 \mathrm{M} \mathrm{Tris}$ ) and incubated at $37^{\circ} \mathrm{C}$ for $30 \mathrm{~min}$, and equal amounts of protein were subjected to substrate-gel electrophoresis. After electrophoresis, the gel was washed twice in $2.5 \%$ Triton X-100 (v:v) and $50 \mathrm{mM}$ Tris- $\mathrm{HCl}(\mathrm{pH} 7.5)$ for $30 \mathrm{~min}$ at room temperature to remove SDS, and incubated in calcium assay buffer ( $50 \mathrm{mM}$ Tris, $10 \mathrm{mM} \mathrm{CaCl}_{2}, 1 \mathrm{mM} \mathrm{ZnCl}, 1 \%$ Triton X-100, $\mathrm{pH} 7.5$ ) for $24 \mathrm{~h}$ at $37^{\circ} \mathrm{C}$. The gel was stained with Coomassie Brilliant Blue R250 in 50\% methanol and $10 \%$ acetic acid and destained in $10 \%$ acetic acid to reveal zones with gelatinase activity. 
Statistical analysis. The bands from RT-PCR, western blotting and gelatin zymography were quantified by MetaView Image Analyzing System (Version 4.50; Universal Imaging Corp., Downingtown, PA, USA). Each experiment was performed in triplicates. Results were presented as mean \pm S.D. Statistical analyses included one-way ANOVA and $t$-test, which were performed using the Statistical Package for Social Science (SPSS for Windows package release 10.0; SPSS Inc., Chicago, IL, USA) and indicated in Results and Figure legends. $P<0.05$ was considered as statistically significant. ${ }^{*} P<0.05 ;{ }^{*} P<0.01$.

\section{Conflict of Interest}

The authors declare no conflict of interest.

Acknowledgements. This study was supported by the 973 Program Grant (2011CB944400) from the Ministry of Science and Technology of the People's Republic of China, National Natural Science Foundation of China Grants (30770816, 31171436 to YT and 81225004 to HMW), the Strategic Priority Research Program and the Knowledge Innovation Program of Chinese Academy of Sciences (XDA01020102 and KSCX2-EW-R-06 to HMW).

1. Vicovac L, Aplin JD. Epithelial-mesenchymal transition during trophoblast differentiation. Acta Anat (Basel) 1996; 156: 202-216.

2. Red-Horse K, Zhou Y, Genbacev O, Prakobphol A, Foulk R, McMaster M et al. Trophoblast differentiation during embryo implantation and formation of the maternal-fetal interface. J Clin Invest 2004; 114: 744-754.

3. Reister F, Frank HG, Kingdom JC, Heyl W, Kaufmann P, Rath W et al. Macrophageinduced apoptosis limits endovascular trophoblast invasion in the uterine wall of preeclamptic women. Lab Invest 2001; 81: 1143-1152.

4. Knofler M. Critical growth factors and signalling pathways controlling human trophoblast invasion. Int J Dev Biol 54: 269-280.

5. Bischof $P$, Meisser A, Campana A. Paracrine and autocrine regulators of trophoblast invasion-a review. Placenta 2000; 21 (Suppl A): S55-S60.

6. Nakayama KI, Nakayama K. Ubiquitin ligases: cell-cycle control and cancer. Nat Rev Cancer 2006; 6: 369-381.

7. Petroski MD, Deshaies RJ. Function and regulation of cullin-RING ubiquitin ligases. Nat Rev Mol Cell Biol 2005; 6: 9-20.

8. Zheng N, Schulman BA, Song L, Miller JJ, Jeffrey PD, Wang P et al. Structure of the Cul1-Rbx1-Skp1-F boxSkp2 SCF ubiquitin ligase complex. Nature 2002; 416: 703-709.

9. Dealy MJ, Nguyen KV, Lo J, Gstaiger M, Krek W, Elson D et al. Loss of Cul1 results in early embryonic lethality and dysregulation of cyclin E. Nat Genet 1999; 23: 245-248.

10. Singer JD, Gurian-West M, Clurman B, Roberts JM. Cullin-3 targets cyclin E for ubiquitination and controls S phase in mammalian cells. Genes Dev 1999; 13: 2375-2387.

11. Li B, Ruiz JC, Chun KT. CUL-4A is critical for early embryonic development. Mol Cell Biol 2002; 22: 4997-5005.

12. Gascoin-Lachambre G, Buffat C, Rebourcet R, Chelbi ST, Rigourd V, Mondon F et al. Cullins in human intra-uterine growth restriction: expressional and epigenetic alterations. Placenta 2010; 31: 151-157.

13. Huber C, Dias-Santagata D, Glaser A, O'Sullivan J, Brauner R, Wu K et al. Identification of mutations in CUL7 in 3-M syndrome. Nat Genet 2005; 37: 1119-1124.

14. Maksimova N, Hara K, Miyashia A, Nikolaeva I, Shiga A, Nogovicina A et al. Clinical, molecular and histopathological features of short stature syndrome with novel CUL7 mutation in Yakuts: new population isolate in Asia. J Med Genet 2007; 44: 772-778.

15. Fu J, Lv X, Lin H, Wu L, Wang R, Zhou Z et al. Ubiquitin ligase cullin 7 induces epithelial-mesenchymal transition in human choriocarcinoma cells. J Biol Chem 2010; 285 : 10870-10879.

16. Wang HX, Wang HM, Lin HY, Yang Q, Zhang H, Tsang BK et al. Proteasome subunit LMP2 is required for matrix metalloproteinase-2 and -9 expression and activities in human invasive extravillous trophoblast cell line. J Cell Physiol 2006; 206: 616-623.
17. Gauster M, Moser G, Orendi K, Huppertz B. Factors involved in regulating trophoblast fusion: potential role in the development of preeclampsia. Placenta 2009; 30 (Suppl A): S49-S54.

18. Kipreos ET, Lander LE, Wing JP, He WW, Hedgecock EM. cul-1 is required for cell cycle exit in C. elegans and identifies a novel gene family. Cell 1996; 85: 829-839.

19. Michel JJ, Xiong Y. Human CUL-1, but not other cullin family members, selectively interacts with SKP1 to form a complex with SKP2 and cyclin A. Cell Growth Differ 1998; 9: 435-449.

20. Staropoli JF, McDermott C, Martinat C, Schulman B, Demireva E, Abeliovich A. Parkin is a component of an SCF-like ubiquitin ligase complex and protects postmitotic neurons from kainate excitotoxicity. Neuron 2003; 37: 735-749.

21. Chan CH, Lee SW, Li CF, Wang J, Yang WL, Wu CY et al. Deciphering the transcriptional complex critical for RhoA gene expression and cancer metastasis. Nat Cell Biol May 12: 457-467.

22. Lala PK, Chakraborty C. Factors regulating trophoblast migration and invasiveness: possible derangements contributing to pre-eclampsia and fetal injury. Placenta 2003; 24 575-587.

23. Varanou $A$, Withington SL, Lakasing L, Williamson C, Burton GJ, Hemberger M. The importance of cysteine cathepsin proteases for placental development. J Mol Med (Berl) 2006; 84: 305-317.

24. Lala PK, Graham CH. Mechanisms of trophoblast invasiveness and their control: the role of proteases and protease inhibitors. Cancer Metastasis Rev 1990; 9: 369-379.

25. Schatz F, Lockwood CJ. Progestin regulation of plasminogen activator inhibitor type 1 in primary cultures of endometrial stromal and decidual cells. J Clin Endocrinol Metab 1993; 77: 621-625

26. Librach CL, Werb Z, Fitzgerald ML, Chiu K, Corwin NM, Esteves RA et al. 92-kD type IV collagenase mediates invasion of human cytotrophoblasts. J Cell Biol 1991; 113: 437-449.

27. Yu C, Shen K, Lin M, Chen P, Lin C, Chang GD et al. GCMa regulates the syncytinmediated trophoblastic fusion. J Biol Chem 2002; 277: 50062-50068.

28. Baczyk D, Drewlo S, Proctor L, Dunk C, Lye S, Kingdom J. Glial cell missing-1 transcription factor is required for the differentiation of the human trophoblast. Cell Death Differ 2009 16: 719-727.

29. Chiang MH, Chen LF, Chen $H$. Ubiquitin-conjugating enzyme UBE2D2 is responsible for FBXW2 (F-box and WD repeat domain containing 2)-mediated human GCM1 (glial cell missing homolog 1) ubiquitination and degradation. Biol Reprod 2008; 79: 914-920.

30. Roberts JM, Cooper DW. Pathogenesis and genetics of pre-eclampsia. Lancet 2001; 357: 53-56.

31. Lain KY, Roberts JM. Contemporary concepts of the pathogenesis and management of preeclampsia. JAMA 2002; 287: 3183-3186.

32. George EM, Granger JP. Recent insights into the pathophysiology of preeclampsia. Expert Rev Obstet Gynecol 2010; 5: 557-566.

33. Zhou Z, Shen T, Zhang BH, Lv XY, Lin HY, Zhu C et al. The proprotein convertase furin in human trophoblast: possible role in promoting trophoblast cell migration and invasion. Placenta 2009; 30: 929-938.

34. Matsuura K, Jigami T, Taniue K, Morishita Y, Adachi S, Senda T et al. Identification of a link between Wnt/beta-catenin signalling and the cell fusion pathway. Nat Commun 2011; 2: 548.

35. Genbacev O, Jensen KD, Powlin SS, Miller RK. In vitro differentiation and ultrastructure of human extravillous trophoblast (EVT) cells. Placenta 1993; 14: 463-475.

36. Soares MJ, Hunt JS. Placenta and trophoblast: methods and protocols: overview II. Methods Mol Med 2006; 122: 3-7.

37. Fu JJ, Lin P, Lv XY, Yan XJ, Wang HX, Zhu C et al. Low molecular mass polypeptide-2 in human trophoblast: over-expression in hydatidiform moles and possible role in trophoblast cell invasion. Placenta 2009; 30: 305-312.

38. Sasaki H, Sheng Y, Kotsuji F, Tsang BK. Down-regulation of X-linked inhibitor of apoptosis protein induces apoptosis in chemoresistant human ovarian cancer cells. Cancer Res 2000; 60: 5659-5666.

Cell Death and Disease is an open-access journal published by Nature Publishing Group. This work is licensed under the Creative Commons Attribution-NonCommercial-No Derivative Works 3.0 Unported License. To view a copy of this license, visit http://creativecommons.org/licenses/by-nc-nd/3.0/ 